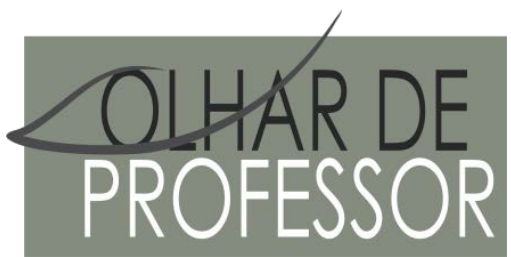

DOI: 10.5212/OLHARPROFR.v.21i1.0010

\title{
PRODUÇ̃̃o DE VÍDEO ESTUDANTIL E APRENDIZAGENS MATEMÁTICAS: UM ESTUDO SEGUNDO OS PRESSUPOSTOS DA TEORIA DAS INTELIGÊNCIAS MÚLTIPLAS
}

\section{STUDENT VIDEO PRODUCTION AND MATHEMATICAL LEARNINGS: A STUDV ACCORDING TO THE ASSUMPTIONS OF THE THEORY OF MULTIPLE INTELLIGENCES \\ PRODUCCIÓN DE VÍDEO ESTUDIANTL Y Y ARRENDIZAJES MATEMÁTICOS: UN ESTUDIO SEGÚN LOS PRESUPUESTOS DE LA TEORÍA DE LAS INTELIGENCIAS MÚLTIPLES}

\author{
COSMERINA ANGÉLICA SOARES CRUZ DE SANTANA * \\ CLAUDINEI DE CAMARGO SANT'ANA **
}

\begin{abstract}
Resumo: Este artigo apresenta os resultados de uma investigação envolvendo estudantes do $2^{\circ}$ ano do Ensino Médionoturno, ao interagirem com a Produção de Vídeo Estudantil (PVE), em uma escola pública de Vitória da Conquista/BA. Foi uma ação no âmbito do Programa de Extensão "Ações Colaborativas e Cooperativas em Educação”, ACCE, do Grupo de Estudos em Educação Matemática (GEEM) da Universidade Estadual do Sudoeste da Bahia (UESB). O desenvolvimento propiciou a criação colaborativa de vídeos com conteúdoMatemáticos, havendo o protagonismo dos estudantes. Para a análise foram considerados os processos de construção, os roteiros, as narrativas e questionários respondidos e os vídeos produzidos pelos estudantes, onde identificou-se, potencialmente, algumas associações envolvendo as inteligências, a saber: a linguística, a lógico-matemática, a espacial, a corporal cinestésica, a intrapessoal, a interpessoal e a musical.
\end{abstract}

Palavras-chave: Produção de Vídeo Estudantil, Teoria das Inteligências Múltiplas, Educação Matemática.

\begin{abstract}
This article presents the results of an investigation involving students of the second year of High School, when interacting with the Student Video Production (PVE), in a public school in Vitória da Conquista/BA. It was an action in the scope of the Extension Program " Ações Colaborativas e Cooperativas em Educação", ACCE, of the Grupo de Estudos em Educação Matemática (GEEM) of the Universidade Estadual do Sudoeste da Bahia (UESB). The development provided the collaborative creation of videos with Mathematical content, with the protagonism of the students. For the analysis we considered the construction processes, the scripts, the narratives and questionnaires answered and the videos produced by the students, where potentially identified some associations involving the intelligences, namely: linguistics, logical-mathematics, spatial, kinesthetic, intrapersonal, interpersonal and musical.
\end{abstract}

Keywords: Student Video Production, Multiple Intelligences Theory, Mathematics Education.

\footnotetext{
* Mestre em Ensino pela Universidade Estadual do Sudoeste da Bahia. Professora de Matemática do Ensino Médio do Colégio Polivalente de Vitória da Conquista. E-mail: angelicasantana7@gmail.com

** Doutor em Educação pela Universidade Estadual de Campinas, com pós-doutoramento pela UNESP. Professor Titular da Universidade Estadual do Sudoeste da Bahia (UESB), campus Vitória da Conquista. E-mail: claudinei@ccsantana.com.
} 
Resumen: En este artículo se presentan los resultados de una investigación que involucra a estudiantes del segundo año de secundaria en la escuela pública de Vitória da Conquista / BA. En el marco del Programa de Extensión " Ações Colaborativas e Cooperativas em Educação", ACCE, del Grupo de Estudos em Educação Matemática (GEEM) de la Universidade Estadual do Sudoeste da Bahia (UESB). El desarrollo propició la creación colaborativa de videos con contenido matemático, habiendo el protagonismo de los estudiantes. Para el análisis se consideraron los procesos de construcción, los guiones, las narrativas y cuestionarios respondidos y los vídeos producidos por los estudiantes, donde se identificó potencialmente algunas asociaciones que involucran las inteligencias, a saber: la lingǘstica, la lógico-matemática, la lógica espacial, la corporal cinestésica, la intrapersonal, la interpersonal y la musical.

Palabras Clave: Producción de Vídeo Estudiantil, Teoría de las Inteligencias Múltiples, Educación Matemática.

\section{INTRODUÇÃO}

Este artigo é resultado de uma pesquisa de mestrado desenvolvida no Programa de PósGraduação em Ensino da Universidade Estadual do sudoeste da Bahia (PPGEn/UESB) em parceria com o Grupo de Estudos em Educação Matemática (GEEM) ${ }^{1}$ e o Programa de Extensão "Ações Colaborativas e Cooperativas em Educação" (ACCE). Apresenta o estudo da Produção de Vídeo Estudantil com conteúdos Matemáticos realizados por alunos do $2^{\circ}$ ano do Ensino Médio noturno em um colégio de Vitória da Conquista/BA.

Os vídeos produzidos foram apresentados na escola e disponibilizados no canal criado no Youtube $^{2}$. Neste processo verificou-se a possibilidade do estímulo e/ou desenvolvimento das inteligências múltiplas associadas ao processo de construção dos vídeos com o protagonismo dos alunos.

Como objetivo principal, esta pesquisa visou responder a seguinte questão: de que forma a Produção de Vídeo Estudantil (PVE), enquanto processo, contribui para o estímulo e/ou desenvolvimento de inteligências que propiciem a aprendizagem de Sequências Numéricas no Ensino Médio?

Procuramos identificar, nos documentos norteadores da prática pedagógica, a proposta de abordagem do conteúdo matemático de Sequências Numéricas e o conjunto de competências e habilidades a serem desenvolvidas pelos alunos, que possibilite uma aprendizagem mais significativa; também verificar a participação dos alunos em cada etapa do desenvolvimento da PVE, da escolha do conteúdo matemático (tema) até a produção de vídeo; avaliar, através da pesquisa escolar, roteiro, questionários, depoimentos e da produção de vídeo, as inteligências estimuladas e/ou desenvolvidas para uma aprendizagem Matemática significativa, analisando os resultados produzidos de maneira individual e em grupo no que se refere à aprendizagem dos alunos e o conteúdo matemático estudado.

Como aporte para fundamentação da pesquisa, apresentamos Ferrés (1996) e Pereira (2008, 2014), no que se refere à Produção de Vídeo Estudantil (PVE). Por conseguinte, discorremos também a Teoria das Inteligências Múltiplas de Gardner (1994) e sua inter-relação com a PVE.

Neste artigo discutimos também os resultados decorrentes da análise do processo e dos conteúdos produzidos, que configuraram as inteligências presentes na diversidade de ações e produtos advindos dos grupos de trabalho dos estudantes, estimuladas e valorizadas no contexto escolar. Desta forma pode-se admitir que a PVE pode ser utilizada como um recurso pedagógico útil para que os estudantes, de forma contextualizada, desenvolvam também de forma autônoma a sua aprendizagem.

\footnotetext{
${ }^{1}$ http://geem.mat.br

${ }^{2}$ https://www.youtube.com/channel/UCK69Pqt1blpvo78-Zk-7dIA?view_as=subscriber
} 


\section{AS TECNOLOGIAS DIGITAIS DE INFORMAÇÃO E COMUNICAÇ̃̃ E A PVE.}

O uso das tecnologias com enfoque pedagógico pode indicar para os professores uma alternativa para atender aos alunos, que estão cada vez mais conectados e envolvidos no mundo digital. Os professores, num processo de reflexão e crítica da sua prática (re)conhece e aproveita esses recursos para incorporar em suas aulas.Assim, a função do docente é a de articular as informações de modo que “[...] combine a inteligência mental e a inteligência sensível com a imaginação criadora”, valorizando os espaços de troca de conhecimentos e construções coletivas em sala de aula (PRETTO, 2013, p. 139). Portanto, é possível que o professor estabeleça a união da teoria e a prática na incorporação com as tecnologias em sala de aula. Essa combinação o habilita a aliar as tecnologias ao seu fazer pedagógico agregando valores étnicos, culturais, pedagógicos e metodológicos à escolha de um recurso mais adequado à sua ação pedagógica. (MERCADO, 2008).

Dentre as tecnologias, tais como a internet, o rádio, o vídeo se destaca no âmbito educacional, pois é considerado, pelos estudantes como uma linguagem agradável e envolvente podendo abordar diversos assuntos. Por isso, os professores podem utilizar a "[...] expectativa positiva para atrair o aluno para os assuntos do nosso planejamento pedagógico” atentando-se para realizar ligações do vídeo com outras dinâmicas trabalhadas em sala de aula. (MORAN, 1995, p. 27).

Ter a atenção dos alunos em tempos de televisão, computadores, internet e redes sociais tem se constituído uma tarefa difícil. Os dados da Pesquisa Brasileira de Mídia (PBM) apontam que a televisão (TV) permanece, de acordo com os entrevistados, como o meio de comunicação mais utilizado para obter informações. Nove em cada 10 (90\%) se referiram à TV como preferência para obter informações (BRASIL, 2016). Entre as faixas etárias de 16 a 17 e 18 a 24 anos, 76\% e 72\%, respectivamente, afirmam assistir TV todos os dias. A popularidade da linguagem audiovisual permite aliar este recurso com a autoria, incentivando e explorando a criatividade dos alunos, bem como a sua capacidade de compreensão e exposição dos conteúdos matemáticos numa linguagem multimodal, que integra imagens, falas, música e escrita. (DEMO, 2008).

O papel do aluno ganha destaque quando se fala em PVE, vídeoprocesso sob a concepção de Ferrés (1996). É ressaltada aqui a importância do protagonismo dos estudantes. O autor destaca o vídeoprocesso como a modalidade em que os estudantes assumem o protagonismo na ação de criação dos vídeos. Desperta o interesse, promove a criatividade, o compromisso, o dinamismo, além de propiciar o trabalho em grupo. Considerado pelo autor uma das formas mais criativas no uso didático do vídeo, que pode e deve ser reinventada a cada dia.

Na PVE, enquanto processo e como estratégia para aprendizagem da Matemática, pressupõe a utilização do trabalho em grupo, onde os estudantes se aproximam conforme o interesse pessoal. Difere de uma aula tradicional, na qual apenas o professor transmite informações. Então um ambiente colaborativo é estabelecido, importante para a valorização de ações tomadas em grupo e todos participam no compartilhamento de informações e conhecimentos.

De certo que todos os membros do grupo são ativos no processo de construção do conhecimento, às vezes assumindo papéis como emissores e em outros como receptores. Isso configura o que Freire (1996) denomina de uma educação, em que há relação entre professor e estudante, de forma dialógica, que se constitui entre sujeitos, e não entre sujeito e objeto, ambos são sujeitos no processo de ensino e aprendizagem. Ele afirma que: “[...] quem ensina aprende ao ensinar e quem aprende ensina ao aprender.” (FREIRE, 1996, p. 12).

A proposta teve como base as atividades desenvolvidas em grupos de cinco a seis estudantes, dentro da perspectiva de se criar um espaço de aprendizagem que promovesse formas interativas e por mediações de resolução de situações problema e ações, que os estudantes não conseguiriam resolver sozinhos, sem a ajuda dos seus pares e/ou da professora.

Nesta modalidade, em colaboração, os alunos produziram os seus próprios vídeos com conteúdo matemático, para posterior apresentação e análise de colegas e professor. As abordagens que podem 
ser dadas aos vídeos pelos alunos são diversas, e Ferrés (1996) as classifica como funções. São elas: Função Informativa tem por finalidade descrever uma realidade mais objetiva possível (vídeodocumento), Na Função Motivadora ou Vídeo animação, o ato comunicativo centra-se no destinatário, procurando atingir, de alguma maneira, sua vontade para aumentar as possibilidades de um determinado tipo de resposta (vídeoanimação), A Função Expressiva - Criatividade e Vídeo arte acontecem quando no ato comunicativo o interesse centra-se primeiro no emissor, que manifesta na mensagem, suas próprias emoções, ou, simplesmente, a si mesmo (criatividade e vídeoarte), Função Avaliadora - Vídeo espelho se refere ao ato de comunicação, no qual o que interessa, fundamentalmente, é a elaboração de valores, atitudes ou habilidades dos sujeitos captados pela câmara (vídeoespelho), A Função Investigativa, o vídeo, por sua configuração tecnológica, é um instrumento especialmente indicado para realizar trabalhos de pesquisa em todos os níveis: sociológico, científico e educativo (trabalhos de pesquisa), A Função Lúdica - Vídeo como Brinquedo, é quando, no ato comunicativo, o interesse se centra basicamente no jogo, no entretenimento, na gratificação e no deleite (o vídeo como brinquedo) e A Função Metalinguística utiliza a imagem em movimento para fazer um discurso a respeito da linguagem audiovisual ou, simplesmente, para facilitar a aprendizagem dessa forma de expressão (uso da linguagem para refletir sobre a própria linguagem). Assim, os estudantes tiveram a liberdade de escolher a função mais adequada para o seu conteúdo, seja documentário, animação, dramatização, telejornal, vídeo aula e na visualização do trabalho poderão fazer uma auto-avaliação.

Há uma expectativa, portanto, que com a aplicação dessa estratégia, ou modalidade, a do vídeoprocesso, o professor consiga propiciar um ambiente, no qual todos possam aprender, de forma solidária, em que aprendam mais, porque todos aprendem com todos. E que se possa assumir o seu papel de sujeito participante e construtor do seu próprio conhecimento. Neste sentido, os estudantes não podem ser espectadores de sua aprendizagem, mas protagonistas. (FREIRE, 1996).

A pedagogia tem que ser fundamentada na ética, no respeito, na dignidade e na autonomia do educando, confrontando a postura de um educador autoritário, que não dialoga com os educandos e desconsidera suas vivências, suas curiosidades e seus questionamentos. (FREIRE, 1996).

Considerando tais aspectos, procurou-se nesta pesquisa desenvolver uma estratégia que considere o estudante como um participante ativo no processo de construção do seu próprio conhecimento. Assim, opta-se pelo vídeoprocesso e "[...] falar de vídeoprocesso equivale falar de participação, de criatividade, de compromisso, de dinamismo.” (FERRÉS, 1996, p. 23). Segundo Ferrés (1996), o vídeoprocesso é uma estratégia de ensino, na qual os estudantes se sentem protagonistas. Nessa modalidade podem ser incluídos os trabalhos de criação artística, de pesquisa, um instrumento lúdico, caracterizando-se em "[...] uma das fórmulas mais criativas do uso didático do vídeo.” (FERRÉS, 1996, p. 23).

Também Pereira (2007), analisou os perfis de professores que produzem vídeos em escolas do município do Rio de Janeiro/RJ. Em outra pesquisa, investigou como a escola utiliza a produção de vídeo, investigando a prática docente comunicacional com o uso dos equipamentos tecnológicos e com a produção de vídeo por um professor e seus alunos dentro do espaço escolar, enfim, um professor com conhecimentos básicos de tecnologia audiovisual pode conduzir o aluno na realização de pesquisas envolvendo a PVE. (PEREIRA, 2014). Em ambas as pesquisas, dentre os resultados foi encontrado o estímulo e desenvolvimento de competências do estudante, tendo o professor na mediação entre estudantes, tecnologias e conteúdos.

\section{A TEORIA DAS INTELIGÊNCIAS MÚLTIPLAS}

Diante de uma concepção bastante difundida e aceita nos anos 1980, de que a inteligência é uma capacidade inata, geral e única, Gardner (1983) propõe a Teoria das Inteligências Múltiplas (TIM). Ele vai além do entendimento de que a inteligência é uma “[...] capacidade ou potencial geral que cada ser 
humano possui em maior ou menor extensão”. Em vez de um único tipo de inteligência, são vários, que não podem ser mensurados por um teste de QI (Quociente de Inteligência), essa crença de que a inteligência "[...] pode ser medida por instrumentos verbais padronizados como testes de respostas curtas realizados com papel e lápis.” (GARDNER, 1994, p. 7).

Pressupõe-se que a descrição e estudos das Inteligências Múltiplas contribuam para um entendimento mais específico dessa temática aos pesquisadores e professores da Educação Básica, na busca de uma melhor compreensão sobre a aprendizagem.

Para Gardner (1994), inteligência é “[...] a capacidade de resolver problemas ou de criar produtos que sejam valorizados dentro de um ou mais cenários culturais.” Considerando essas capacidades enumerou, inicialmente, sete "estruturas da mente" ou inteligências, não determinando o número preciso delas. Para ele, “[...] há pelo menos algumas inteligências, que estas são relativamente independentes umas das outras e que podem ser modeladas e combinadas numa multiplicidade de maneiras adaptativas por indivíduos e culturas." (GARDNER, 1994, p. 7). Parte do pressuposto de que todo indivíduo possui certas habilidades em todas as inteligências e o desenvolvimento dessas é determinado tanto por fatores genéticos, quanto por fatores ambientais e culturais. Inicialmente identificou sete inteligências: Inteligência Linguística, Inteligência Lógico-Matemática, Inteligência Espacial, Inteligência Corporal-Cinestésica, Inteligência Musical, Inteligência Interpessoal e a Inteligência Intrapessoal.

Estudos mais recentes trazem avanços, com a expansão das inteligências, como a oitava, chamada Inteligência Naturalista e começa também a discutir a possibilidade de uma nona, denominada Inteligência Existencial. (ARMSTRONG, 2001).

Uma das qualidades mais caras da teoria das Inteligências Múltiplas é como ela possibilita diferentes caminhos para a aprendizagem. Se um professor está tendo dificuldade em alcançar um estudante nas formas de instrução Lógica Matemática ou Linguística, por exemplo, que são mais tradicionais, sugere-se formas variadas pelas quais o professor pode adequar o conhecimento a ser ensinado, apresentando-o de forma diferente para facilitar a aprendizagem do estudante.

Por exemplo, se você está ensinando ou aprendendo sobre a relação entre grandezas, você pode ler sobre ou criar uma história e representá-la artisticamente (Linguística), estudar fórmulas matemáticas que a expressam (Lógica-Matemática), examinar uma tabela gráfica que representa esse conceito matemático (Espacial), observe a lei no mundo natural (Naturalista) ou no mundo humano da economia (Interpessoal), examine a relação em termos de seu próprio corpo (Corporal-Cinestésico e Intrapessoal), e/ou escrever uma música (ou encontrar uma música existente), que demonstre tal relação.

Obviamente que não é necessário se valer de todas as oito ou nove maneiras constantes nas inteligências múltiplas, pode-se apenas visualizar e em seguida, decidir quais caminhos seguir, de acordo com as ferramentas de ensino ou formas de aprendizagem mais eficazes. Esse é um dos benefícios dessa teoria, expandir as possibilidades e o uso de ferramentas de ensino e aprendizagem disponíveis para além dos métodos tradicionais que utilizam apenas recursos linguístico e ou lógico matemáticos (por exemplo, aulas expositivas, livros didáticos, trabalhos de escrita, dentre outros).

Uma das implicações pedagógicas da TIM se refere à avaliação. Para Gardner (1995) ela deve ser contextualizada, realizada durante o processo de aprendizagem do aluno. A avaliação beneficia o levantamento de dados e informações dos estudantes em seu cotidiano, momento em que o estudante pode mostrar as suas capacidades, e ainda que a avaliação deve ser de fato válida, ou seja, feita em ambientes conhecidos e deve utilizar materiais conhecidos das crianças que estão sendo avaliadas.

Nesta investigação, foram considerados estudantes do Ensino Médio, que presumidamente não apresentam distúrbios cerebrais. Nos trabalhos em grupo, uma combinação das seguintes inteligências: linguística, lógico-matemática, espacial, corporal-cinestésica, intrapessoal e interpessoal, musical e naturalista. 


\section{METODOLOGIA}

A produção dos vídeos com situações problema envolvendo conteúdos Matemáticos teve como base o entendimento de que os alunos aprendem de forma individualizada e pluralizada. Assim o processo de construção configuraria em uma oportunidade diversificada de aprendizagem de forma livre e autônoma, despertando o potencial criativo e intelectual dos estudantes.

As etapas de produção dos vídeos implicam: a) formação dos grupos de trabalho; b) escolha do conteúdo; c) estudo do conteúdo sob a orientação da professora; d) elaboração de um trabalho escrito sobre o conteúdo escolhido; e) participação em um curso sobre a produção de vídeos; f) elaboração de roteiro com base no curso e no conteúdo em estudo; g) captação de imagens, vídeos e áudios; h) tratamento e edição das imagens, vídeos e áudios; i) apresentação da primeira versão do vídeo para a professora; j) apresentação da versão final para os demais colegas, em sala de aula.

O trabalho foi desenvolvido coletivamente, por grupos, geralmente de 6 a 7 estudantes, formação de livre escolha dos componentes, segundo o relacionamento interpessoal da turma, a professora interveio quando necessário.

Os temas foram discutidos juntamente com os estudantes durante o trimestre para cada grupo. Foi requisitado, que individualmente fizessem uma pesquisa escolar do conteúdo, em livros didáticos, em sites relacionados com Matemática e canais do youtube indicados pela professora e, posteriormente compartilhados no grupo para estudo e síntese, para a estruturação de um trabalho escrito e entregue à professora servindo como base para a elaboração do roteiro.

Todos os alunos participaram de um curso "Matemática em Vídeo" de produção e edição de vídeos promovido pelo Grupo de Estudos em Educação Matemática (GEEM), no âmbito (GEEM) do Programa de Extensão Ações Cooperativas e Colaborativas em Educação (ACCE).

Cada etapa foi acompanhada e avaliada, os estudantes utilizaram recursos próprios (celulares inteligentes, câmera digital, local fora do colégio para gravação, aplicativos e softwares para edição e animação de vídeos e outros) para suas produções audiovisuais.

O curso abordou a pré-produção, a produção e a pós-produção dos vídeos. Durante o curso cada grupo teve inicialmente a concepção da ideia do vídeo, escrevendo, em no máximo cinco linhas, a história criada, escolheram o gênero ou estilo do vídeo, se animação, documentário, jornal ou outros. A partir da concepção e criação supracitadas, os grupos elaboraram o roteiro de um vídeo de até dez minutos, incluídos o título e os créditos e entregaram uma versão impressa ou digital para correções, adequações e sugestões.

As correções foram sugeridas e o roteiro devolvido para que fosse colocado em execução, com a captura de imagens, vídeos e áudios. Após as filmagens, organização das imagens e áudios, utilizados nos vídeos, começou a fase da edição. Como já comentado, eles utilizaram recursos próprios como celulares (smartphones), tablets, notebooks com dispositivos e ou aplicativos de gravação, edição e reprodução de vídeos e os disponibilizados pela professora, como notebook e data-show. Ficaram livres para escolher o aplicativo ou software preferido para essa tarefa. O sugerido e utilizado foi o Windows MoovieMaker, que embora seja um software proprietário, é disponibilizado gratuitamente pela Microsoft, nos computadores pessoais com a plataforma Windows.

Foi estabelecido uma data específica a todos os grupos para a entrega da primeira versão do vídeo, havendo uma primeira análise e solicitação de correções necessárias. A apresentação da versão final foi realizada em um único dia, na sala de vídeo da escola, com a turma de $2^{\circ}$ ano Ensino Médio do colégio, no turno noturno.

Cada atividade foi avaliada e discutida com os grupos em reuniões semanais de orientação, momento em que os estudantes de cada grupo tiveram a oportunidade de relatarem, em áudio gravação, um pouco da percepção que eles tiveram da atividade desenvolvida em cada etapa do trabalho. 
O projeto teve como enfoque pedagógico, o estudo de temas e conteúdos matemáticos, envolvendo Sequências Numéricas, mediados pela elaboração e resolução de situações-problema relacionadas com o contexto dos alunos. Os Parâmetros Curriculares Nacionais: Matemática (BRASIL, 1997, p. 32) indicam a resolução de problemas como um ponto de partida importante e fundamental a ser desenvolvida nas aulas de Matemática. Essas situações problema foram abordadas de uma forma diferenciada e criativa, associadas à realidade dos estudantes, mediados pelas TDIC, que exercem papel importante no processo de ensino e aprendizagem.

Juntos, professora e estudantes puderam utilizar as ferramentas matemáticas e tecnológicas para compreender o fenômeno estudado. Assim, todos aprimoraram os conhecimentos prévios, adquiriram habilidades e desenvoltura no tratamento das ferramentas tecnológicas voltadas à produção de vídeo para o ensino e aprendizagem de Matemática.

Os materiais produzidos foram: o trabalho escrito e/ou impresso do tema matemático estudado, o roteiro do vídeo, os depoimentos gravados ao final de cada etapa, o vídeo produzido e apresentado. Foram utilizados smartphones dos estudantes e uma câmera fotográfica da professora para fotos e vídeo durante as atividades realizadas em sala de aula.

Os dados produzidos nesta pesquisa estão sendo analisados por meio da análise temática de conteúdo, segundo Bardin (2009), a partir da análise temática dos conteúdos presentes nos dados expostos aqui, será possível categorizar os eixos centrais das implicações pedagógicas da produção de vídeos matemáticos com o protagonismo do estudante. Para que haja uma aplicação coerente da análise de conteúdo, é necessária uma organização, em consonância com os requisitos de uma interpretação de um enunciado e mensagens, as fases organizam-se em torno de três passos: " 1 . A préanálise; 2. A exploração do material; e, por fim, 3. O tratamento dos resultados: a inferência e a interpretação.” (BARDIN. 2009, p. 121).

A pré-análise consiste no período de sistematização, ou seja, além da escolha dos documentos que serão submetidos à análise, se fará também a formulação de hipóteses para construção de parâmetros para a interpretação final. Para tanto, foram escolhidas amostras das questões abertas dos questionários e dos depoimentos gravados em áudio relacionados às percepções dos alunos sobre a PVE, enquanto processo, como estímulo e/ou desenvolvimento de inteligências em aprendizagens Matemáticas. Para um trabalho proficiente a pesquisadora esteve atenta às amostras que se apresentaram representativas e importantes para o alcance dos objetivos da pesquisa. "A análise pode efetuar-se numa amostra desde que o material a isso se preste. A amostragem diz-se rigorosa se a amostra for uma parte representativa do universo inicial.” (BARDIN, 2009, p. 123).

Nesse sentido o material foi organizado por etapas do desenvolvimento do trabalho, os dados dos questionários foram tabulados, os depoimentos gravados em áudio foram transcritos, as leituras exploratórias foram realizadas visando identificar nas falas dos alunos indicadores que serviram como possíveis respostas aos objetivos propostos por esta investigação.

Após a leitura das fontes e identificação de temas recorrentes e relevantes aos objetivos deste estudo, foi realizada a categorização das informações, orientadas pelo problema, objetivos e referencial teórico adotado.

A terceira e última fase traduz-se no tratamento dos resultados: inferência e interpretação. Etapa cuidadosa, em que se decidiu de forma aplicada sobre os dados de maneira a realizar uma análise crítica e reflexiva segundo os pressupostos da TIM.

\section{UMA ANÁLISE SEGUNDO OS PRESSUPOSTOS DA TIM}

As análises a seguir têm como base as respostas dadas ao questionário e os depoimentos dados pelos estudantes nas entrevistas. 
Entendemos que a TIM pode auxiliar no contexto da sala de aula, com estudantes, cada vez mais conectados às tecnologias digitais, possibilitando maior inclusão desses recursos nos processos de ensino e aprendizagem, assim a utilizamos também para análise das atividades, segundo aspectos apresentados à seguir.

\section{INTELIGENCIA LINGUISTICA}

De acordo com a respostas dadas ao questionário e com os depoimentos e o diário de campo, observamos que a PVE proporcionou maior aplicação dos conceitos teóricos matemáticos, ampliou os conhecimentos e melhorou a habilidade de comunicação. Os estudantes foram estimulados a fazer pesquisa escolar e estudar o conteúdo a ser abordado em vídeo, de maneira que a produção do vídeo implicou na socialização com seus pares e a professora. De certo que foi uma inovação para os mesmos criar uma situação problema dentro do seu contexto, da sua realidade e retratá-la em uma história; elaborar um roteiro de vídeo com essa história; produzir um vídeo com o estilo ou modalidade que mais o agradasse e chamasse a atenção dos colegas; atuar como apresentadores e atores nas gravações e exibir o vídeo produzido, em classe, mostrando e esclarecendo aos colegas o que aprenderam do conteúdo matemático solicitado. Ao propor e efetivar cada uma dessas ações foi possível estimular ou desenvolver a inteligência linguística. Isso podemos evidenciar no depoimento de Karina, componente do grupo 3, “[...] e com o vídeo a gente teve mais tempo de pesquisar, fazer o roteiro de uma forma mais engraçada pra que todo mundo conseguisse entender da maneira mais simples que a gente poderia mostrar no nosso dia a dia e tal.”

A estudante demonstra satisfação em trabalhar o conteúdo matemático de forma mais autônoma e livre para criar um roteiro, que apresentasse uma linguagem mais simples e contextualizada à sua realidade e dos colegas.

\section{INTELIGENCIA LÓGICO-MATEMÁTICA}

Em se tratando da inteligência lógico-matemática, pode-se identificar essa em cada situação problema elaborada nos grupos, apresentaram habilidades para relacionar o conteúdo matemático proposto a contextos do seu dia a dia, reconhecer padrões e fazer generalizações. Isto se percebe no exemplo do roteiro do grupo 2:

\footnotetext{
"As cadeiras estão dispostas de forma triangular. Temos ao todo 7 (sete) fileiras, na primeira fileira nós temos 6 cadeiras e na última fileira nós temos 18 cadeiras. As fileiras obedecem à formação de uma PA, acrescendo sempre duas cadeiras a cada fileira."
}

Eles reconheceram, em uma situação da realidade deles, o conceito de uma Progressão Aritmética-PA. A cada fileira disposta no auditório eram acrescidas duas cadeiras e esse padrão se estendia até a última fileira, levando-os a estabelecer uma relação ao conteúdo pesquisado e estudado no início do processo de construção do vídeo. Observa-se nessa construção que foram para além do conteúdo matemático proposto, trabalhando a geometria por intermédio da modelagem gráfica do auditório.

No questionário a PVE facilitou o entendimento dos conteúdos da disciplina, proporcionou maior aplicação dos conceitos teóricos matemáticos, a atividade contribuiu, significativamente, para um melhor desempenho na disciplina, ajudou a desenvolver habilidades para resolução de problemas. 


\section{INTELIGEENCIA CORPORAL-CINESTÉSICA}

Para a PVE, a linguagem corporal é muito importante, pois essa está relacionada às expressões, posturas e gestos que utilizam o corpo. As pessoas que apresentam a inteligência corporal cinestésica, geralmente, gostam de praticar esportes, utilizam frequentemente a linguagem corporal. O grupo 3 apresentou uma situação problema envolvendo um ciclista, que pretendia melhorar seus rendimentos físicos::

Lucas (com sua bicicleta) encontra-se com seu empresário Matheus discutindo sobre o progresso do seu treino.

- Lucas: Matheus eu resolvi percorrer $30 \mathrm{~km}$ no meu primeiro dia, e ao longo dos dias 10 minutos. Será que em um mês eu consigo?

- Matheus: vamos usar uma progressão para a aprendizagem e a descobrir se Lucas consegue alcançar sua meta.

Lucas, componente do grupo 3, é um ciclista e vivencia esta situação problema na realidade e não sabia que a Matemática poderia ajudá-lo a melhorar o seu rendimento. Na troca de ideias, com o seu grupo, pode relacionar o conteúdo matemático de forma prática para sua realidade.

\section{INTELIGÊNCIA ESPACIAL}

Quando o aluno está com sua câmera ou smartphone na mão fazendo um enquadramento de uma cena, ele está utilizando a sua capacidade de perceber com precisão o mundo visuoespacial. Ele consegue criar representações tridimensionais e perceber as transformações que o espaço sofre. Podese verificar isso no roteiro do grupo 2, quando esquematizaram, em desenho tridimensional, o auditório (figura 2) triangular para melhor visualização dos agrupamentos de cadeiras e o acréscimo, em progressão aritmética de cada fileira, facilitando a resolução do problema.

\section{Figura 1 - Auditório}

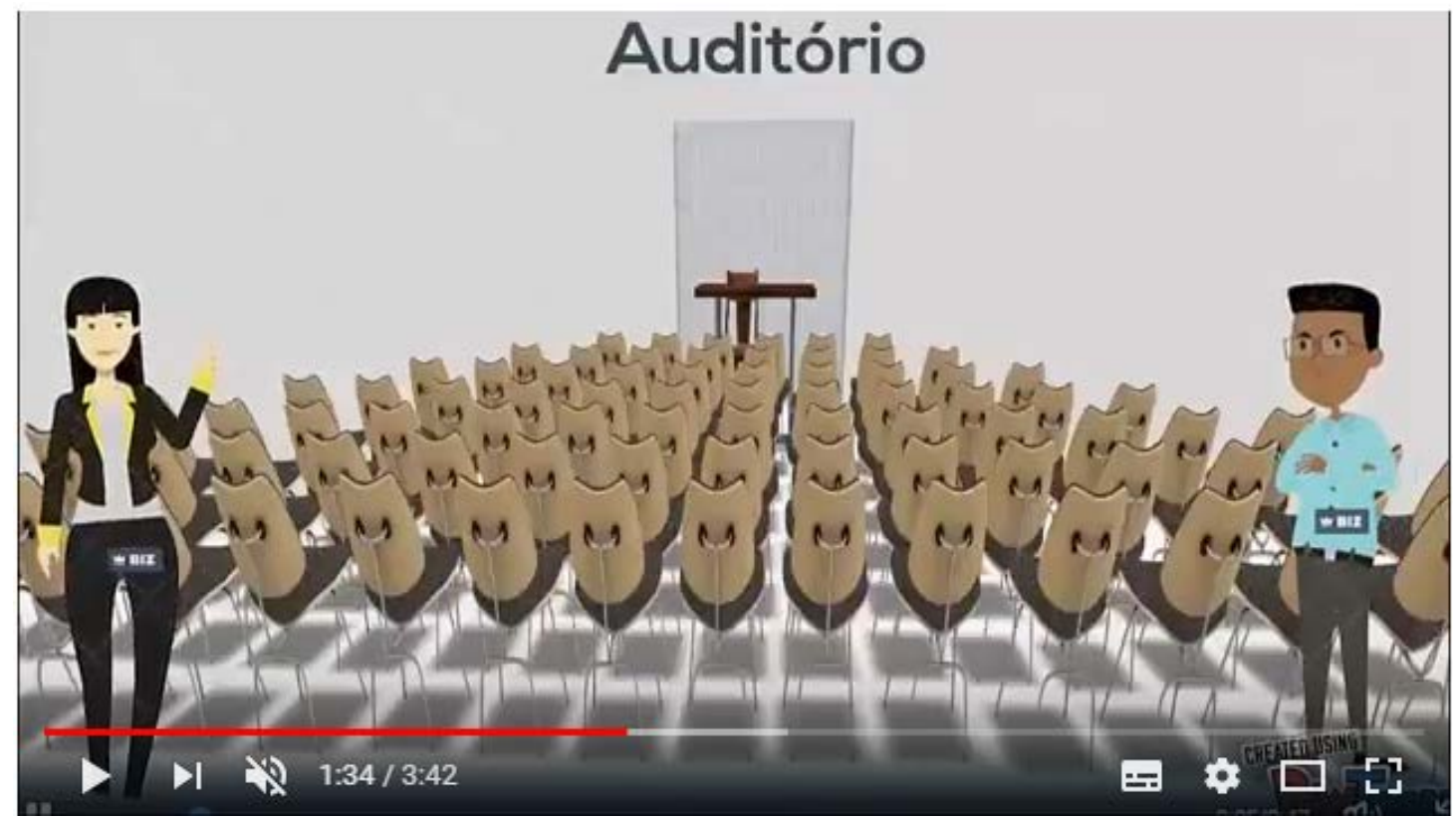

Fonte: Acervo da autora (2018)

Em entrevista com uma das estudantes componente do grupo 2, foi relatado que pretendiam gravar no auditório da escola, mas verificaram que ele não apresentava as características necessárias para representar o problema. Antes, tentaram reproduzir a disposição do auditório pretendido com as 
cadeiras na sala de aula, desistiram da ideia por questão de estética, não gostaram do resultado. Finalmente, resolveram fazer a representação gráfica do espaço num programa de design de interiores, modelando assim satisfatoriamente a situação. Essa é a inteligência espacial colocada em prática e que tem uma relação bem aproximada com a Matemática, no que se refere ao espaço e a forma.

\section{INTELIGENNCIA MUSICAL}

Os estudantes que apresentam a inteligência musical mais desenvolvida gostam de escutar, produzir e reproduzir músicas, e apresentam sensibilidade e habilidade para discernir sons, ritmos e timbres, dão maior sentido a temas musicais. No grupo 1, um dos componentes relacionou o seu gosto pelas músicas do seu conjunto de rock preferido às Sequências Numéricas. Colocou um pequeno trecho de uma das músicas desse conjunto como abertura do seu vídeo, segundo ele, para chamar a atenção daqueles que viriam a assistir ao vídeo. Em seu depoimento, afirmou: “[...] costumo ter em meu celular várias músicas do Gun’sand Roses, de vários álbuns, que formam uma sequência”, daí ele resolveu criar uma situação problema abordando uma sequência de músicas da sua lista.

A música é um elemento importante na PVE, pois desperta sensações, emoções e torna o vídeo mais atraente ao espectador, para isso é necessário que a mesma seja escolhida de forma a se adequar a uma trilha sonora propícia à ideia, ao conteúdo que se deseja transmitir.

\section{INTELIGENCIA INTERPESSOAL E INTRAPESSOAL}

O trabalho em grupo proporcionou situações, nas quais os alunos puderam estabelecer uma proximidade com seus colegas, socializar ideias, conhecimentos, saberes e dúvidas. As inteligências intra e interpessoal, segundo as respostas do questionário 5, foram as mais estimuladas, pois a PVE despertou maior interesse pela disciplina, incentivou a criatividade, favoreceu uma maior interação entre os colegas de sala, potencializou as habilidades de trabalhar em equipe, melhorou a comunicação, ajudou a desenvolver as habilidades de liderança, de planejamento, despertou a motivação, o entusiasmo em participar desta atividade e a enfrentar obstáculos. Observemos o depoimento da aluna Karina do grupo 3, a seguir:

Eu gostei bastante da PVE, pois às vezes a gente não tem vontade de estudar sobre o assunto e tal...e procurar também uma forma de ensinar pra outras pessoas...é de uma maneira mais fácil porque muitas vezes a gente tá tentando apresentar na sala de aula e o aluno não presta atenção porque é de uma forma muito dura né? Vai na cara dura assim, você tem que prestar atenção de uma forma mais direta.

Na declaração anterior, encontramos indícios do que Cosenza e Guerra (2011) afirmam sobre as emoções. Segundo seus estudos, as emoções devem ser consideradas nos processos educacionais de modo a promover as emoções positivas e evitar as negativas, em benefício da aprendizagem. $\mathrm{O}$ desenvolvimento dos aspectos da emoção são características das inteligências intra e interpessoais de Gardner (1995) e pode influenciar o desenvolvimento das demais inteligências.

\section{INTELIGÊNCIA NATURALISTA E EXISTENCIAL}

Não foram identificadas, neste trabalho, as inteligências naturalista e existencial, embora possam ser desenvolvidas dentro da PVE atividades que envolvam a Matemática ligada ao meio ambiente e preservação da natureza, bem como de se situar em relação a elementos da condição e existência humana. 
É importante ressaltar que para Gardner (1994), embora as inteligências sejam relativamente independentes, elas raramente funcionam isoladamente. Assim, percebe-se que ao incentivar o desenvolvimento das IM nas aulas de Matemática se poderá estimular o desenvolvimento da inteligência Lógico-matemáticas nos alunos, que supostamente possam apresentar pouco interesse por essa matéria e não tenham essa inteligência desenvolvida.

\section{CONSIDERAÇÕES E PERSPECTIVAS}

Dado a maneira como os estudantes se mostravam ao se envolverem nas produções e apresentações, mesmo relacionadas com o conteúdo matemático relativo à cada vídeo produzido, notou-se que a PVE, como prática pedagógica, pode fazer com que o aluno progrida e se sinta motivado a aprender pelo prazer em aprender, de certo que: “A produção audiovisual desperta a motivação, através da produção de vídeo feita pelos estudantes [...] Essa motivação é um elemento importante dentro do espaço educacional.” (PEREIRA, 2014, p. 200).

Na PVE os alunos trilharam as etapas de planejamento, estudo, contextualização e criação. Dentro da etapa da contextualização tentaram aproximar a Matemática formal e a Matemática fora da escola. Esse foi um momento crucial no aprendizado de conceitos matemáticos, visto que necessitaram fazer a aplicação prática, na construção dos vídeos.

A etapa da criação levou o aluno a deixar a passividade e assumir uma postura mais ativa, em interação com os colegas e mediado pelo professor no desenvolvimento da sua aprendizagem. Neste protagonismo é possível despertar o interesse, a curiosidade pelo novo e a criatividade, bem como estimular e ou desenvolver diversas habilidades e inteligências nos estudantes envolvidos no processo, como: inteligências linguística, lógico-matemática, espacial, corporal-sinestésica, musical, intra e interpessoal. Estas duas últimas inteligências ficaram mais evidentes devido à aplicação da PVE, pois se favoreceu o trabalho em grupo, promovendo a interação entre os colegas, melhorando as habilidades de comunicação e de liderança, diminuindo a timidez e elevando a auto-estima dos alunos envolvidos na ação.

A PVE foi considerada pelos estudantes como um método dinâmico e que proporciona autoaprendizagem. Essas são contribuições que podem melhorar o interesse, o aproveitamento e o rendimento na disciplina, principalmente, na Educação Básica, segmento que compreende um contexto de alunos cada vez mais conectados às tecnologias digitais.

Por desenvolver a pesquisa no ensino noturno, um dos maiores entraves foi em relação ao desempenho dos alunos, muitos justificaram sua baixa disposição alegando cansaço do trabalho e pela falta de tempo. O que decorreu em atrasos na entrega das atividades propostas por alguns grupos de trabalho, demandando prorrogação de datas previstas pela professora.

Como desafios futuros, é possível indicar: como incentivar colegas professores a perderem o medo de utilizar as tecnologias digitais a seu favor e da aprendizagem do aluno? Como sair da zona de conforto e adotar estratégias que levem os alunos a aprenderem de forma significativa? Como disponibilizar, por exemplo, um ensino híbrido para os alunos, com aulas presenciais e remotas, em que os professores poderiam desenvolver seus próprios vídeos e enviá-los para os alunos? proporcionando uma otimização do tempo deles.

Com relação à PVE, analisar: quais modalidades e abordagens de utilização de vídeo mais se adequam aos processos de ensino e aprendizagem de conteúdos matemáticos na Educação Básica, em especial, no Ensino Médio? Como avaliação, ela é um instrumento importante nos processos de ensino e aprendizagem de Matemática?

Diante de tudo isso, pode-se depreender que o desenvolvimento da PVE para o professor se constitui em um grande desafio e uma grande recompensa. O desafio de sair de sua zona de conforto, por trabalhar com um público que tem maior domínio das TDIC que ele. 


\section{REFERENCCIAS}

ARMSTRONG, T. Inteligências múltiplas na sala de aula. Porto Alegre: Artes Médicas, 2001.

BARDIN, L. Análise de conteúdo. Lisboa: Edições 70, 2009.

BRASIL. Presidência da República. Secretaria de Comunicação Social. Pesquisa brasileira de mídia 2016: hábitos de consumo de mídia pela população brasileira. Relatório final. Brasília: IBOPE Inteligência, 2016. 162 p.

BRASIL. Secretaria de Educação Fundamental. Parâmetros Curriculares Nacionais: Matemática. Brasília: MEC/SEF, 1997. 142 p.

DEMO, P. Os desafios da linguagem do século XXI para o aprendizado na escola. Palestra, Faculdade OPET, jun. 2008. Disponível em: http://www.nota10.com.br. Acesso em: 30 jun. 2016.

FERRÉS, J. Vídeo e educação. Porto Alegre: Artes Médicas, 1996.

FREIRE, P. Pedagogia da autonomia: saberes necessários à prática educativa. São Paulo: Paz e Terra, 1996.

GARDNER, H. Inteligências múltiplas: a teoria na prática. Porto Alegre: Artes Médicas, 1995.

GARDNER, H. Estruturas da mente: a teoria das inteligências múltiplas. Porto Alegre: Artes Médicas, 1994.

MERCADO, L. P. L. Práticas de formação de professores na educação a distância. Maceió: UFAL, 2008.

MORAN, J. M. O vídeo na sala de aula. Comunicação \& Educação, São Paulo, v. 2, p. 27-35, jan./abr. 1995.

PEREIRA, J. P. A produção de vídeo estudantil na prática docente: uma forma de ensinar. 2014, 220 f. Tese (Doutorado em Educação) - Faculdade de Educação, Universidade Federal de Pelotas, Pelotas, 2014.

PEREIRA, J. P. Novas tecnologias de informação e comunicação em redes educativas. Londrina: ERD Filmes, 2008.

PEREIRA, J. P. A produção de vídeo em escolas: um estudo sobre o perfil dos professores que trabalham com a criação de vídeos em escolas do município do Rio de Janeiro. 2007, $123 \mathrm{f}$. Dissertação (Mestrado em Educação) - Programa de Pós-Graduação em Educação, Universidade Federal do Estado do Rio de Janeiro, Rio de Janeiro, 2007.

PRETTO, N. de L. Uma escola com/sem futuro: educação e multimídia. Campinas: Papirus, 2013.

\section{AGRADECIMENTOS:}

Aos membros do Grupo de Estudos em Educação Matemática (GEEM) e do Programa de Extensão "Ações Colaborativas e Cooperativas em Educação” (ACCE), em especial à professora Irani Parolin Sant'Ana pela colaboração na redação final deste. 